\title{
A EDUCAÇÃO AMBIENTAL NO CONTEXTO DA EVOLUÇÃO DA CIÊNCIA, TECNOLOGIA E SOCIEDADE
}

\author{
Daniela Brusamarelo ${ }^{1}$ \\ Luciene Lima de Assis Pires ${ }^{2}$ \\ Sandra Regina Longhin ${ }^{3}$ \\ Angélica Ramos da $\mathrm{Luz}^{4}$ \\ Dilene Gomes de Miranda ${ }^{5}$ \\ Instituto Federal de Educação, Ciência e Tecnologia de Goiás, Campus Jataí.
}

\begin{abstract}
RESUMO
A sociedade contemporânea se defronta com a problemática ambiental decorrente de um sistema econômico baseado na exploração de recursos naturais, na produção, no consumo e no acúmulo de capital. Neste contexto, este artigo buscou em sua parte inicial expor uma breve revisão do cenário econômico e social nos quais evoluem a ciência e a tecnologia, a relação com os impactos ambientais. A preocupação com os rumos desta evolução, no âmbito das questões ambientais evidenciadas, faz surgir movimentos internacionais, a partir da década de 1960, em que são debatidos os rumos do desenvolvimento, as implicações, a busca de soluções para a crise ambiental. No segundo momento são evidenciados os impactos ambientais decorrentes da relação entre a produção, o consumo e o descarte de materiais, situação insustentável que leva ao consenso sobre o perigo à vida planetária. O caráter transformador da educação é abordado na parte final, como um caminho para a promoção de uma educação ambiental crítica que contemple o diálogo, a reflexão crítica, o exercício da cidadania, a superação da economia de exploração, a compreensão do mundo e da vida com vistas à sua complexidade.

Palavras-chave: Ambiente; Economia; Educação; Impacto Ambiental; Sociedade.
\end{abstract}

\section{ENVIRONMENTAL EDUCATION IN THE CONTEXT OF DEVELOPMENT OF SCIENCE, TECHNOLOGY AND SOCIETY}

\begin{abstract}
Contemporary society is confronted with environmental problems arising from an economic system based on the exploitation of natural resources, in the production, consumption and capital accumulation. In this context, this article sought in its initial part to present a brief review of the economic and social scenario in which science and technology evolve, the relationship with environmental impacts. Concern about the direction of this evolution, within the ambit of the environmental issues highlighted, gives rise to international movements, starting in the 1960s, in which the course of development, the implications and the search for solutions to the environmental crisis are discussed. In the second moment the environmental impacts resulting from the relationship between production, consumption and disposal of materials are evidenced, an unsustainable situation leading to a consensus on the danger to planetary life. The transforming character of education is approached in the final part, as a way to promote a critical environmental education that contemplates dialogue, critical reflection, exercise of citizenship, overcoming the economy of exploration, understanding the world and life With a view to its complexity.
\end{abstract}

Keywords: Environment; Economy; Education; Environmental Impact; Society. 


\section{Introdução}

A ciência ocidental tem suas raízes na Grécia com as escolas filosóficas do período pré-socrático, que, estendendo-se à posteridade, fundamentaram as bases para a ciência moderna e a contemporânea. Com a consolidação da ciência moderna, em meados do século XVI, a sociedade instituiu o paradigma mecanicista, pautado na explicação matemática da realidade, na objetividade, na certeza, na neutralidade (THUILLIER, 1994).

Neste contexto histórico foi estabelecido o sistema econômico capitalista que, de forma gradativa e acelerada nos últimos séculos, se sustenta a partir da exploração de recursos naturais, produção de bens e consumo, objetivando o acúmulo de capital de grupos sociais minoritários. A sociedade foi transformada para atender a lógica capitalista, que incorporou no sistema produtivo os artefatos tecnológicos, a princípio para contribuir com a industrialização de países do Norte. Em decorrência, esse período marca o início de profundas transformações no ambiente natural e no modo de vida das populações.

A partir da segunda metade do século XX, os impactos causados pelo homem ao ambiente são evidenciados e destacados pela mídia jornalística, adquirindo relevância. Nesse período ocorre uma tomada de consciência por parte da sociedade sobre a problemática ambiental vivenciada. Um dos fatores que contribuíram para esta percepção foi a publicação do livro Primavera Silenciosa, no ano de 1962, pela bióloga Rachel Carson, que evidenciava os impactos decorrentes da utilização do pesticida diclorodifeniltricloroetano (DDT) na agricultura.

A temática ambiental passa a ser debatida em conferências internacionais em busca de soluções para a crise ambiental, sendo a precursora de tais eventos, a Conferência Mundial sobre o Meio Ambiente Humano, realizada em Estocolmo, no ano de 1972. Na conferência, foram debatidos os problemas ambientais, para os quais se esperavam respostas dos países participantes, principalmente quanto ao esgotamento de recursos e as mudanças climáticas, decorrentes do desenvolvimento econômico vigente. Este evento foi o marco que oficializou a importância de vincular a educação e o ambiente em caráter global.

Com o avanço do desenvolvimento tecnológico, frente ao cenário de degradação ambiental vivenciado, a preocupação entendeu-se aos rumos tomados pela evolução da ciência e a da tecnologia com vistas às questões ambientais. Em decorrência, surge o movimento ambiental Ciência, Tecnologia e Sociedade (CTS), na década de 1970, que aponta a educação como um dos caminhos possíveis para a transformação desta realidade, por meio de uma concepção crítica da sociedade atual (VAZ; FAGUNDES; PINHEIRO, 2009).

Entendendo a necessidade da inclusão da Educação Ambiental (EA) no ensino, esta foi consolidada no I Seminário Internacional de Educação Ambiental, realizado em Belgrado, na Iugoslávia, no ano de 1975. Neste evento, estabeleceu-se a necessidade da incorporação da EA no ensino formal e não-formal, como um processo contínuo e permanente; a compreensão do ambiente como um conjunto em que interagem as dimensões do mundo natural, do mundo criado pelo homem, a ecológica, a econômica, a social, a legislativa, a cultural, a estética.

A contextualização econômica e social no qual evolui a ciência e a tecnologia, relatando as implicações ao meio ambiente decorrentes da produção, do consumo e do descarte de materiais, assim como os desafios para a EA na sociedade contemporânea, na busca de uma nova racionalidade ambiental, é o objetivo deste artigo de revisão. 


\section{Evolução da ciência, tecnologia e sociedade}

O desenvolvimento da ciência e da tecnologia são realizações humanas, historicamente situadas, seguindo os pressupostos teóricos e paradigmáticos construídos no decorrer do processo civilizacional. Quando em meados do século XVII, a ciência, a filosofia e a economia se voltaram para o mesmo interesse, que era o de estabelecer o domínio do homem sobre a natureza, com o predomínio do paradigma mecanicista. Este paradigma proporcionou a consolidação do progresso e com ele decorre a evolução das tecnologias. A solidificação do sistema capitalista inglês, no século XVIII, tem atuação crucial neste cenário, na medida em que universalizou as relações de dependência e alienação, preparando a sociedade para o trabalho e para o consumo de tecnologias (IANNI, 1988).

A crescente industrialização, iniciada nos países do Norte, desencadeou um processo de transformação ambiental e social sem precedentes em todo o orbe. Com a problemática ambiental posta em evidência por estudiosos e pela mídia jornalística, a preocupação com os rumos desta transformação passa a ser tema de conferências internacionais. O movimento CTS surge nesse contexto com enfoque na preocupação com os rumos da evolução científica e tecnológica no desenvolvimento da sociedade e suas implicações ambientais (VAZ; FAGUNDES; PINHEIRO, 2009).

Este contexto econômico e social promove a evolução e incorporação das tecnologias, que como já mencionado, são construções humanas, logo, imbuídas de valores, sentidos e interesses distintos. No contexto econômico do trabalho, as tecnologias têm sido incorporadas visando à eficiência e o aumento da produtividade do trabalhador, atendendo aos interesses do mercado controlado por uma elite dominante. Demasiadamente, as tecnologias permeiam o contexto social de tal forma que não se imagina neste século XXI, uma sociedade sem energia, meios de comunicação e artefatos tecnológicos (FOUREZ, 1995).

O processo evolutivo das tecnologias no cotidiano da sociedade merece um olhar atento das ciências sociais, para a compreensão de sua extensão e de seu lugar na sociedade e na história (FONSECA, 2007). A submissão e a passividade a cada exigência tecnológica imposta, a cada novo produto disponibilizado, sem ao menos questionar se este produto agregará valores positivos ou negativos acentuou-se no século XXI.

Some-se a isto, a racionalidade econômica dominante que, para manter seu ritmo de crescimento, apregoa o discurso de que as tecnologias, em suas diversas aplicações, são a solução para resolver problemas como a escassez de recursos naturais, o tratamento de rejeitos, a fome no mundo. Tal discurso se encontra arraigado de tal forma na sociedade que a tecnologia, de forma cada vez mais freqüente, tem se apresentando como uma resposta mesmo que a sociedade não tenha feito nenhuma pergunta (BAZZO, 1998).

Acerca das formas de interação entre a sociedade e a ciência, das quais decorre a evolução científica e tecnológica, o filósofo alemão Jürgen Habermas, organizou-as como o modelo tecnocrático, o decisionista e o pragmático-político, cada qual com suas vantagens e limitações. Dentre estes modelos, o pragmático defende o debate permanente sobre a evolução tecnológica entre especialistas da área e não especialistas, onde na tomada de decisões, por meio de negociações políticas, é levada em consideração a opinião de ambos os lados. Considera, ainda, que a compreensão e participação da sociedade quanto às tecnologias são fundamentais para a discussão recente acerca do condicionamento da existência individual e social à tecnologia, tanto material quanto intelectual, e quais os rumos tomados com tal evolução (HABERMAS, 1973 apud FOUREZ, 1995). 
A realidade aqui exposta é a de que a sociedade se transforma também com base na interação com a tecnologia que desenvolve, modificando os hábitos, as relações sociais e ambientais. O contraponto é que dificilmente se busca estudar e entender a nova sociedade que será formada. A sociedade que não compreende a ciência, tampouco conseguirá debater em situações e tomadas de decisão imediatas e futuras. Do mesmo modo não perceberá que a própria ciência é o meio pelo qual ideologias podem ser criticadas e seus limites expostos (BAZZO, 1998).

\section{A relação entre produção, consumo e descarte: consequências ambientais globais}

O predomínio do sistema econômico capitalista tem contribuído para aprofundar as modificações ocorridas na natureza e nas práticas sociais contemporâneas. É também inerente a esta sociedade a evolução tecnológica, que contribui para a transformação das formas de comunicação, de interação social, de trabalho, de apropriação do espaço natural. Em meio a tal evolução, esta sociedade é também conceituada como sociedade da informação ou tecnológica.

Convém destacar que, para atingir esse patamar evolutivo e tecnológico, pretendido pelo sistema econômico vigente, são utilizados recursos naturais esgotáveis em grande escala; o trabalho é explorado marcadamente em países subdesenvolvidos; são acentuadas as desigualdades de acesso aos recursos naturais, aos bens produzidos, a distribuição dos riscos ambientais entre as diferentes classes sociais e entre nações. Nesse sentido, é premente que a evolução da ciência e da tecnologia ocorra com vistas à sustentabilidade; as novas formas de socialização e redefinições de identidade cultural e coletiva precisam ser repensadas com urgência (VAZ; FAGUNDES; PINHEIRO, 2009).

Uma justificativa que grande parcela da sociedade contemporânea encontra para explicar o consumo exacerbado de tecnologias é o sentido de liberdade atribuído aos artefatos, pelo simples fato de existir e apregoar ser, assim como existem os argumentos de que muitas estão plenamente solidificadas em nossa sociedade e em contextos que escapam da nossa capacidade de escolha e controle como, por exemplo, a televisão, os meios de transporte e a energia elétrica (BAZZO, 1998). Uma concepção ingênua frente aos reais interesses de governos e corporações para o desenvolvimento e incorporação das tecnologias na sociedade.

A economia vigente desvincula os problemas ambientais e econômicos, incentiva o consumo de recursos naturais e materiais e o aumento das desigualdades, como mencionado anteriormente. Uma análise feita na Índia considerando diferentes classes econômicas, realizada em 2009, aponta que mesmo com a renda anual de $\mathrm{R} \$ 4,850$ por pessoa em termos de paridade do poder de compra (PPC), muitas residências têm acesso a iluminação básica e a um ventilador. Com $\mathrm{R} \$ 9,700$ ao ano, o acesso à televisão passa a ser padrão e o acesso aos aquecedores de água cresce. Com $\mathrm{R} \$ 15,520$ ao ano, a maioria das pessoas dispõe de ampla gama de bens de consumo (WORLDWATCH INSTITUTE, 2010). Ou seja, o aumento do PPC influencia diretamente na aquisição de novos bens e produtos.

Notadamente, a forma que o sistema econômico encontrou para sustentar e elevar o acúmulo de capital foi manter produtos circulando, por meio da baixa durabilidade dos mesmos e o estímulo ao consumo, oferecendo versões melhoradas de um mesmo produto. Em relação às tecnologias eletroeletrônicas, culmina com o descarte da tecnologia antecessora, aumentando as estatísticas de produção de lixo eletrônico. Neste aspecto, o Brasil tem posição de destaque na América Latina, enquanto consumidor de produtos eletrônicos e como o maior produtor dos resíduos decorrentes destes, sendo que este 
cenário não vislumbra mudanças. O primeiro mapa de lixo eletrônico mundial coordenado pela Organização das Nações Unidas (ONU) apontou o Brasil como responsável pela produção de 1,4 milhão de toneladas deste lixo em 2012, dentre as 49 milhões de toneladas produzidas mundialmente. A produção brasileira de lixo eletrônico foi de $7 \mathrm{~kg} / \mathrm{habitante}$ (ONU, 2012).

A propósito de uma compreensão sobre a demanda de recursos naturais necessários para a produção de tecnologias, na fabricação de um único computador juntamente com o seu monitor de 17' (polegadas), ambos pesando em média $24,0 \mathrm{~kg}$, é utilizado 10 vezes o seu próprio peso em combustível fóssil, aproximadamente $22,0 \mathrm{~kg}$ de produtos químicos e 1,5 toneladas de água. Assim, no total, são necessárias aproximadamente 1,8 toneladas de matéria prima para produzir um único computador (MATTOS; MATTOS; PERALES, 2008).

O percurso deste ciclo, que sustenta a economia, se inicia com a exploração predatória de matérias-primas, passa pelo processo de produção em larga escala, a distribuição, até o consumidor final, com a terminalidade no descarte de resíduos. Durante todo este processo o ambiente é impactado em suas diversas dimensões, com ênfase na promoção de "uma escassez global induzida pela expansão econômica" (LEFF, 2013, p. 49).

Os impactos ambientais ocasionados pela expansão do processo de globalização econômica, afetam profundamente o equilíbrio do planeta na medida em que são adotadas práticas predatórias de recursos naturais, a produção em larga escala, o estímulo ao consumo de bens e produtos. Por meio do marketing e de estratégias como a obsolescência planejada e a obsolescência perceptiva, o sistema conduz a sociedade para a manutenção do ciclo que o sustenta, aumentando as desigualdades tanto de acesso aos bens produzidos entre as diferentes classes sociais, quanto da responsabilização pelos impactos ambientais ocasionados.

De fato, o estímulo deste sistema ao consumo dos bens naturais e materiais, é o meio para justificar e retroalimentar a cadeia produtiva, e como uma de suas conseqüências, eleva o descarte de resíduos que impactam o ambiente de forma insustentável e leva ao consenso sobre o perigo à vida planetária em toda a sua complexidade. O relatório Estado do Mundo 2013 aponta como impactos ambientais sérios, ocasionados principalmente pela emissão de gases poluentes e produção de resíduos, a seca em vários países, poluição do ar, desertificação dos solos, aumento do nível dos oceanos, emissão de gases do efeito estufa, temperatura e migração de populações para outras regiões do planeta (WORLDWATCH INSTITUTE, 2013).

O aumento populacional, o desenvolvimento tecnológico, o industrial, o processo de urbanização crescente, por sua vez, promovem o aumento contínuo na produção per capita de resíduos sólidos. O acúmulo e o descarte destes resíduos trazem uma série de problemas ao ambiente ao desencadearem eventos que afetam o equilíbrio planetário. Em maior ou menor grau todas as formas de vida, o funcionamento de todos os ecossistemas é impactado. Especificamente, no tocante aos resíduos eliminados a céu aberto e sem o tratamento adequado, estes promovem o desenvolvimento de microorganismos, de doenças, a produção de líquido percolado (chorume), de gases, a contaminação de recursos hídricos.

Dentre os resíduos, os sólidos orgânicos obtidos do consumo e do processamento de alimentos é a categoria que mais contribui em quantidade desperdiçada e descartada no ambiente. O desperdício decorre de fatores como o manuseio inadequado, a falta de condições de armazenagem e transporte, de tecnologias de conservação e principalmente 
pela má utilização dos alimentos. Estes resíduos se constituem em uma problemática dos grandes centros de consumo e se acumulam em toneladas, produzidas diariamente.

Outros problemas ambientais relacionados ao descarte de resíduos sólidos decorrem da queima de lixo a céu aberto, que produz substâncias químicas altamente tóxicas como a dioxina; de líquidos percolados; da atração de animais vetores; da ação de microorganismos patogênicos. Os resíduos lançados em cursos d'água poderão ocasionar assoreamento, aumento da turbidez e variação de temperatura, acarretando a quebra do ciclo vital das espécies, tornando a água biologicamente estéril. A poluição biológica das águas, a partir de altos índices de coliformes fecais e resíduos que produzem transformações biológicas consideráveis, influencia diretamente a qualidade de vida do ecossistema aquático e dos que dele tiram seu sustento (ALBUQUERQUE NETO et al., 2007).

O desperdício de alimentos é outro fator de prejuízo socioambiental com sérias conseqüências, sendo que 1,3 bilhão de toneladas são desperdiçadas anualmente (ONU, 2013). A quantidade de alimentos produzidos é mais do que suficiente para alimentar toda a população global de forma saudável, mas o desperdício faz com que a produção diária de 4,600 kcal/pessoa seja revertida num total de 2,000 kcal/pessoa disponíveis para o consumo diário. Mais da metade dos alimentos produzidos tornam-se lixo orgânico em função do manuseio e infraestrutura inadequados, da infestação de pragas em produções agrícolas e de seu mau uso (ONU, 2011).

A produção, o processamento, a comercialização, o consumo e a eliminação têm importantes externalidades ambientais. A energia e a utilização de recursos naturais, associados aos gases de efeito estufa ocorrem principalmente durante a fase de produção dos alimentos e são os mais impactantes para o ambiente. A ONU alerta, ainda, para as discrepâncias no consumo de alimentos e os padrões de geração de resíduos (ONU, 2013).

Em outras palavras, chama a atenção para a desigualdade de acesso aos alimentos e os hábitos alimentares entre as nações desenvolvidas e subdesenvoldas. O estímulo ao consumo excessivo de alimentos, principalmente os de origem animal como a carne e os devirados lácteos, em determinadas nações, levam a expansão das fronteiras agrícolas de países em desenvolvimento para a produção de grãos em larga escala, a expansão da pecuária, em atendimento a este mercado. Os impactos decorrentes são fundamentalmente a perda da biodiversidade local e regional, a emissão de gases poluentes, o aquecimento global.

O aumento da temperatura da superfície do planeta, por sua vez, é resultado direto da transformação no espaço natural pelo homem, por meio da exploração e do consumo dos recursos naturais, da queima de combustíveis fósseis, do desenvolvimento tecnológico, da expansão da fronteira agrícola. Assim, embora as populações do globo não impactem o planeta em mesmo nível, o aquecimento global é um problema complexo, ou seja, impacta o ambiente em sua totalidade. $\mathrm{O}$ discurso de países capitalistas e industrializados, ainda na década de 1970, responsáveis por utilizar 20,0\% de toda área agrícola do planeta, era o de que a hidrosfera e a atmosfera seriam contaminadas a partir de resíduos produzidos no próximo século, se considerando uma população de cerca de 10 bilhões de habitantes. No entanto, os 500 milhões de habitantes da Europa Ocidental e da América do Norte causavam neste mesmo período tantos impactos para o ambiente quanto o fariam possivelmente dez bilhões de indianos (BOSQUET, 1976).

As consequências impactantes ao ambiente causadas em decorrência de políticas públicas atreladas à ordem econômica predominante indicam a continuidade do processo de produção, do consumo e geração de resíduos, da agressão ao ambiente. A falta de atuação social na coletividade frente à este panorama, de fiscalização atuante e com caráter 
punitivo pelos órgãos responsáveis, a falta de consciência ambiental refletem de forma negativa na qualidade de vida e saúde pública da população, e de todos os organismos vivos, sugerindo medidas para a reversão deste quadro em caráter de urgência.

É fundamental consolidar o entendimento de que a exploração do ambiente natural, a fabricação e o consumo de materiais, expressivamente de artefatos tecnológicos são ações humanas, condicionadas ao predomínio econômico. Desta forma, no coletivo da sociedade devem emergir novos valores de apropriação da natureza, a ressignificação da economia, buscando a sustentabilidade do processo, posto que os impactos ao ambiente são complexos o que por sua vez exigem soluções igualmente complexas (JARROSSON, 1996).

\section{Pressupostos para uma educação ambiental transformadora}

A efetivação da EA no sistema formal de ensino brasileiro ainda está em sua alvorada. No cenário nacional tanto a Constituição Federal, as Diretrizes Curriculares Nacionais (DCN) e a Lei de Diretrizes e Bases da Educação Nacional (LBD) preconizam o direito e obrigatoriedade da EA em todos os níveis de ensino, em âmbito formal e nãoformal, o seu caráter transversal, contínuo e permanente. As DCN, em consonância com a LDB, prevêem nos currículos do Ensino Fundamental e Médio a formação básica do cidadão para a compreensão do ambiente natural e social, o conhecimento do mundo físico e natural e a preparação para o exercício da cidadania (BRASIL, 2013).

Embora incorporada à legislação nacional e nos documentos que orientam à educação, para Loureiro (2012) a construção histórica da EA no Brasil seguiu em um viés conservacionista, influenciado por valores da classe média européia. A problemática ambiental foi associada à preservação do patrimônio natural, em um assunto técnico voltado para a resolução de problemas, um entrave para o desenvolvimento do país, reflexos que foram incorporados na educação formal.

Complementa que faltou o entendimento de uma EA como resultante de um movimento histórico. A ausência da reflexão sobre seus propósitos e significados políticos, levou os educadores ambientais a adotarem tendências conservadoras pragmáticas, estabelecendo ações educativas que dissociaram o social do natural. Entendendo que a educação possui essência dialógica, ou seja, tanto reproduz a ideologia dominante quanto a desmascara (FREIRE, 1996), no âmbito da incorporação da EA no ensino, assumiu o caráter de reprodutora ideológica das forças dominantes, promovendo o desenvolvimento tecnológico neutro, a ingenuidade sobre as relações que permeiam a sociedade e o ambiente.

Ao passo que o caráter desmascarador da escola a constitui em espaço para a transformação, a criatividade, a curiosidade, a compreensão de como o ser humano se organiza socialmente e se integra a natureza (FREIRE, 1996). Por meio de sua função social, potencializa os questionamentos e reflexões sobre a realidade em um processo de crítica, autocrítica, política e conscientização coletiva; a EA por sua vez integra a educação buscando contrapor concepções e tendência solidificadas, entender e viabilizar novos patamares societários e civilizacionais (LOUREIRO, 2012).

A educação necessita emancipar o educando para romper com o alheamento econômico e político inerente à dinâmica da relação sociedade e ambiente. No âmbito do desenvolvimento tecnológico, trata-se de transformar a concepção de uma sociedade que acredita que quanto maior for à produção científica e tecnológica do país, maior será a geração de riquezas e por conseqüência o bem-estar social (VAZ; FAGUNDES; PINHEIRO, 2009). 
Desde modo, tratar da problemática ambiental na educação envolve a concepção de ambiente como um conjunto integrado de processos históricos, econômicos, sociais, políticos, tecnológicos, ecológicos e culturais. Leff (2002) propõe como um passo inicial para se chegar a este entendimento, a realização de um diagnóstico dos efeitos dos processos de reprodução e acúmulo de capital, dos impactos ambientais das práticas atuais de produção e consumo, da formação social dos países em desenvolvimento e a valorização da exploração de seus recursos.

Trata-se da formação crítica do cidadão, com entendimento e reconhecimento profundo da sua relação com o ambiente, ainda na formação básica. O desenvolvimento de habilidades mentais é premente para perceber que a sociedade contemporânea se organiza sob a égide do sistema econômico que não possui limites ou formas de controle; acelera a produção de riquezas materiais, alienadas, pois atendem à reprodução e o acúmulo de capital; se apropria de forma desigual do patrimônio natural; da distribuição desigual dos riscos ambientais; do acesso aos bens produzidos; que não externaliza o real custo dos produtos.

Na educação formal básica trata-se, ainda, de vincular os conteúdos e as práticas pedagógicas. Por meio da abordagem interdisciplinar, buscar o desenvolvimento da habilidade de perceber o mundo como um conjunto de sistemas complexos, para compreender as causas e efeitos, a interdependência e a indeterminação dos diferentes processos (LEFF, 2013).

Em relação à abordagem da EA na aprendizagem das ciências, em seu conceito amplo, demanda superar concepções distorcidas e empobrecidas da ciência e da tecnologia, que são socialmente aceitas. A educação deve priorizar na formação dos educandos oportunidades para analisar a situação de emergência em que se encontra o planeta e considerar as possíveis soluções (CACHAPUZ et al., 2005).

A relação entre a sociedade e a natureza é a essência da EA. Assim, o educador, para intervir adequadamente, necessita considerar as múltiplas facetas, diversas e complementares, que compõe essa relação. $\mathrm{O}$ ambiente deve ser considerado em suas diferentes concepções: como natureza, como recurso, como problema, como sistema, como lugar para se viver, como biosfera e como projeto comunitário, pois a EA que se limita a apenas uma destas concepções se torna incompleta e limitada (SAUVÉ, 2005b).

O desenvolvimento de habilidades, tanto para o professor quanto para o educando, é necessário para perceber as relações econômicas e políticas que conduzem a dinâmica social. Nesse sentido, as práticas pedagógicas tradicionais do professor transmissor de conhecimentos e do educando passivo devem ser superadas no sentido de um ensino problematizador, libertador e desalienador que defende a autonomia da construção do conhecimento e promove a transformação no pensar e agir do ser humano em sua relação com o mundo (FREIRE, 1987).

Corrobora com a concepção freireana de educação Loureiro (2012) ao entender que uma educação ambiental sob a ótica transformadora. Sendo considerada um elemento de transformação social, necessita estabelecer suas bases no diálogo, no exercício da cidadania, no fortalecimento do sujeito, na superação das formas de dominação capitalistas e na compreensão do mundo e da vida em toda sua complexidade.

De acordo com esta concepção de ensino, o desenvolvimento científico e tecnológico, o fazer da ciência e a responsabilidade da sociedade com o ambiente, necessitam mobilizar a coletividade, em seus diversos segmentos sociais para a compreensão de que compartilham objetivos em comum. A formação de consciência ecológica, a participação da sociedade na gestão de recursos ambientais, o planejamento da administração pública e a reorganização interdisciplinar do saber, tanto na produção quanto 
na aplicação do conhecimento, é um conjunto de processos sociais que devem ser considerados pelo todo (LEFF, 2013).

Notadamente, a EA tem sido realizada na educação formal por meio de concepções e práticas distintas, conduzindo a resultados também diversos, embora predomine a concepção conservadora/recursista (LEFF, 2013; LOUREIRO, 2012). No intuito de interpretar tais concepções, estas têm sido categorizadas na forma de correntes (como se concebe e se pratica a EA) diversas como a conservadora, a pragmática, a crítica, a da sustentabilidade (SAUVÉ, 2005a).

Entendendo que a EA segue por caminhos diversos, os apontamentos aqui expostos, que almejam uma educação transformadora, encontram sustentação na corrente de EA com abordagem crítica. Tal abordagem contrapõe o modelo de Educação Conservadora; revela a dominação tanto do homem quanto da natureza; as relações de poder na sociedade contemporânea; defende a politização da sociedade para a transformação social almejando o equilíbrio socioambiental, que se dará por meio do exercício do diálogo, da ação-reflexão-ação.

\section{Considerações finais}

A sociedade se constitui como produtora e consumidora de bens materiais em uma economia baseada na superexploração de recursos naturais, em que o repensar sobre essas práticas é premente. O consumismo, principalmente de artefatos tecnológicos, poderá aumentar proporcionalmente em função da elevação da renda per capita do indivíduo e os impactos ambientais gerados pela produção e descarte inadequado de resíduos comprometem todas as formas de vida no planeta.

O movimento CTS e a EA defendem o estímulo ao pensamento crítico e reflexivo do educando para a construção de uma nova racionalidade, que não conceba a ciência e a tecnologia meramente a serviço do desenvolvimento econômico, mas como possibilidade para considerar a sustentabilidade dos processos com vistas ao desenvolvimento futuro.

A educação que retrata e reproduz a sociedade também projeta o futuro pretendido. Constitui-se em motor da mudança para a transformação social ao considerar o conjunto das dinâmicas que envolvem as esferas cultural, ecológica, econômica, tecnológica e política. As mudanças almejadas na escola envolvem todo o ambiente educacional e deve estar integrada aos demais segmentos da sociedade.

A Educação Ambiental se constitui de itinerários que fornecem subsídios para o desenvolvimento de uma nova racionalidade ambiental. Em seu viés crítico A EA pretende o entendimento do sujeito em sua relação com a natureza, o exercício da cidadania, a defesa dos princípios da solidariedade, igualdade e diversidade, a participação efetiva da coletividade, a apreensão de que um desenvolvimento sustentável será possível somente a partir do rompimento com o pensamento racionalista econômico dominante.

\section{Referências}

ALBUQUERQUE NETO, Hélio Cavalcanti et al. Caracterização de resíduos sólidos orgânicos produzidos no restaurante universitário de uma instituição pública (estudo de caso). In: Encontro Nacional de Engenharia de produção, 27, Foz do Iguaçu.

Resumos... Foz do Iguaçu: Associação Brasileira de Engenharia de Produção, 2007. Disponível em: 〈http://www.abepro.org.br/biblioteca/enegep200_r650481_0422.pdf>. Acesso em: 05 out. 2015. 
BAZZO, Walter Antonio. Ciência, tecnologia e sociedade e o contexto da educação tecnológica. Florianópolis: Editora da UFSC, 1998.

BOSQUET, Michel. Ecologia e Política. Lisboa: Editorial Notícias, 1976.

BRASIL. Ministério da Educação. Diretrizes curriculares nacionais gerais da educação básica. Brasília: MEC, SEB, DICEI, 2013. Disponível em: <

http://portal.mec.gov.br/index.php?option=com_docman\&view=download\&alias=15548d-c-n-educacao-basica-nova-pdf\&Itemid=30192 > . Acesso em: 29 out. 2015.

CACHAPUZ, Antonio et al.(Orgs.). A renovação necessária do ensino de ciências. São Paulo: Cortez, 2005.

FONSECA, Alexandre Brasil. Ciência, tecnologia e desigualdade social no Brasil: contribuições da sociologia do conhecimento para a educação em ciências. Revista Eletrónica de Enseñanza de Las Ciências, v. 6, n. 2, p. 364-377, 2007.

FOUREZ, Gerard. A construção das ciências, uma introdução à filosofia e ética das ciências. Trad. de Luiz Paulo Rouanet. São Paulo: Editora Unesp, 1995.

FREIRE, Paulo. Pedagogia do oprimido. 17. ed. Rio de Janeiro: Paz e Terra, 1987. Paz e Terra, 1996.

Pedagogia da Autonomia: saberes necessários à prática educativa. São Paulo:

IANNI, Otávio. Dialética e capitalismo: ensaio sobre o pensamento de Marx. 3. ed. Revista e aumentada em 7 capítulos. Petrópolis: Vozes, 1988.

JARROSSON, Bruno. Humanismo e técnica: o humanismo entre economia, filosofia e ciência. Trad. Isabel de Almeida Brito. Lisboa: Instituto Piaget, 1996.

LEFF, Enrique. Epistemologia ambiental. Trad. Sandra Valenzuela. 5. ed. São Paulo: Cortez, 2002.

. Saber ambiental: sustentabilidade, racionalidade, complexidade, poder. Trad. Lúcia Mathilde Endlich Orth. 10. ed. Rio de Janeiro: Vozes, 2013.

LOUREIRO, Carlos Frederico B. Trajetórias e fundamentos da educação ambiental. 4. ed. São Paulo: Cortez, 2012.

MATTOS, Karen Maria da Costa; MATTOS, Katty Maria da Costa; PERALES, Watson José Saenz. Os impactos ambientais causados pelo lixo eletrônico e o uso da logística reversa para minimizar os efeitos causados ao meio ambiente. In: Encontro Nacional de Engenharia de Produção, 28., 2008, Rio de Janeiro. Anais... Rio de Janeiro: ABEPRO, 2008. Disponível em: <http://www.abepro.org.br/biblioteca/enegep2008_tn_stp_077_543 11709.pdf >. Acesso em: 05 nov. 2015.

ONU. Programa das nações unidas para o meio ambiente. Caminhos para o desenvolvimento sustentável e a erradicação da pobreza: síntese para tomadores de decisão. 2011. ISBN: 978-92-807-3204-7. Disponível em:

<http://www.unep.org/greenconomy>. Acesso em: 03 ago. 2014. 
E-waste worldmap. 2012. Disponível em: <http://www.stepinitiative.org/index.php/Overview_Brazil.html>. Acesso em: 12 jul. 2014.

Food and Agricultural Organization. Food wastage footprint: impacts on natural resources. 2013. Disponível em: 〈http://www.fao.org/docrep/018/i3347e/i3347e.pdf〉. Acesso em: 16 out. 2015.

SAUVÉ, Lucie. Uma cartografia das correntes em Educação Ambiental. In: SATO, Michèle; CARVALHO, Isabel C. Moura (Orgs.). Educação Ambiental. Porto Alegre: Artmed, 2005a, p. 17- 44.

Educação ambiental: possibilidades e limitações. Educação e Pesquisa, São Paulo, v. 31, n. 2, p. 317-322, 2005 b.

THUILLIER, Pierre. De arquimedes a einstein: a face oculta da invenção científica. Rio de Janeiro: Jorge Zahar Ed, 1994.

WORLDWATCH INSTITUTE. Estado do Mundo 2010: transformando culturas: do consumismo à sustentabilidade. Relatório anual 2010. 1. ed. Bahia: UMA, 2010. Disponível em: 〈http://www.wwiuma.org.br/estado_2010.pdf >. Acesso em: 30 nov. 2015.

\section{Estado do Mundo 2013: a sustentabilidade ainda é}

possível?. Relatório anual 2013. 1. ed. Bahia: UMA, 2013. Disponível em: <http://www.akatu. org.br/Content/Akatu/Arquivos/file/EstadodoMundo2013web.pdf $>$. Acesso em: 30 nov. 2015.

VAZ, Caroline Rodrigues; FAGUNDES, Alexandre Borges e PINHEIRO, Nilcéia A. Maciel. O surgimento da ciência, tecnologia e sociedade (CTS) na educação: uma revisão. In: Simpósio Nacional de Ensino de Ciência e Tecnologia, 1., 2009, Curitiba. Anais... Curitiba, 2009. ISBN: 978-85-7014-048-7. Disponível em: <http://www.sinect.com.br/anais2009/artigos/1\%20CTS/CTS_Artigo8.pdf >. Acesso em: 30 nov. 2015.

\section{Notas}

\footnotetext{
${ }^{1}$ Mestranda do Programa de Pós-Graduação em Educação para Ciências e Matemática do Instituto Federal de Educação, Ciência e Tecnologia de Goiás, Campus Jataí.

2 Doutora em Educação. Professora do Programa de Pós-Graduação em Educação para Ciências e Matemática do Instituto Federal de Educação, Ciência e Tecnologia de Goiás, Campus Jataí.

${ }^{3}$ Doutora em Química. Professora do Programa de Pós-Graduação em Educação para Ciências e Matemática do Instituto Federal de Educação, Ciência e Tecnologia de Goiás, Campus Jataí.

${ }^{4}$ Mestranda do Programa de Pós-Graduação em Educação para Ciências e Matemática do Instituto Federal de Educação, Ciência e Tecnologia de Goiás, Campus Jataí.

${ }^{5}$ Mestranda do Programa de Pós-Graduação em Educação para Ciências e Matemática do Instituto Federal de Educação, Ciência e Tecnologia de Goiás, Campus Jataí.
}

Recebido: março/16 Aprovado: dezembro/16 